\title{
Efeito do Tratamento Térmico Pós-Soldagem nas Propriedades Mecânicas e Microestruturais de Metal de Solda de Aço de Extra Alta Resistência para Utilização em Equipamentos de Ancoragem
}

\author{
(Effect Of Post Welding Heat Treatment on the Mechanical and Microstructural Properties of Extra High Strength Steel Weld \\ Metals for Mooring Equipments Application)
}

\author{
Jorge Carlos Ferreira Jorge ${ }^{1,3}$, Sérgio Maciel Faragasso ${ }^{1}$, Luís Felipe Guimarães de Souza ${ }^{1}$, Ivaní de Souza Bott ${ }^{2}$, \\ ${ }^{1}$ CEFET/RJ, DIPPG, Rio de Janeiro, RJ, Brasil,jorgecfjorge@gmail.com,sergio.faragasso@gmail.com,lfgs59@gmail.com, \\ ${ }_{2}^{2}$ PUC-Rio, DEMA, Rio de Janeiro, RJ, Brasil, bott@puc-rio.br \\ ${ }^{3}$ Fluke Engenharia Ltda., Diretoria Técnica, Rio de Janeiro, RJ, jorge.jorge@flukeengenharia.com.br
}

\section{Resumo}

Realizou-se a avaliação de metal de solda com resistência a tração superior à 860MPa, para utilização na soldagem de aço grau R4 da norma IACS W22. Para tanto, foram soldadas juntas multipasse com preaquecimentos realizados à 200 e $250^{\circ} \mathrm{C}$ pelo processo eletrodo revestido, utilizando um consumivel com 4,0mm de diâmetro e cuja composição base é C-0,06\%, Mn-1,89\%, e Ni-2,95\%. Após a soldagem foram realizados ensaios mecânicos e metalográficos em corpos-de-prova retirados integralmente do metal depositado nas condições de como soldado e após tratamento térmico pós-soldagem realizados à $600^{\circ} \mathrm{C}$ por 2 horas. Os resultados mostraram que os metais de solda obtidos apresentaram propriedades mecânicas adequadas para todas as condições de análise, propiciando resultados superiores aos mínimos requeridos para a utilização na soldagem do aço grau $R 4$ utilizados em equipamentos de ancoragem de plataformas de petróleo. A análise metalográfica permitiu clarificar a microestrutura presente e explicar o comportamento das propriedades mecânicas após o tratamento térmico.

Palavras-chave: Metal de Solda, Propriedades Mecânicas, Tratamento Térmico Pós-Soldagem

\begin{abstract}
A weld metal with tensile strength higher than 860 MPa for the welding of a IACS W22 R4 Grade Steel was evaluated. Welded joints with preheat of 200 and $250^{\circ} \mathrm{C}$ were produced by SMAW process using $4.0 \mathrm{~mm}$ diameter covered electrodes in multipass technique whose basic composition was: $\mathrm{C}-0,06 \%, \mathrm{Mn}-1,89 \%$, e Ni-2,95\%. After welding, mechanical and metallographic tests were done in allweld metal samples in both as-welded and post welded heat treatment conditions performed at $600^{\circ} \mathrm{C}$ for 2 hours. The results show that the obtained weld metals have mechanical properties higher than the minimum required for the welding of a IACS W22 R4 Grade steel in all condition analysis, which makes possible to attain an adequate strength/toughness relationship for high strength steel applied in mooring equipments. The metallographic analysis allowed the identification of microstructure and, consequently, the behavior of the mechanical properties after post weld heat treatment.
\end{abstract}

Key-words: weld metal, mechanical properties, post weld heat treatment

\section{Introdução}

A expansão da indústria do petróleo no Brasil, fez com que as atividades offshore tivessem um grande impulso, dado que as maiores reservas petrolíferas brasileiras encontram-se em águas profundas. Neste cenário, para a exploração do petróleo nestas condições, são utilizadas plataformas semi-submsersíveis, as quais são posicionadas com auxílio de sistemas de ancoragem, que consistem de diversos equipamentos, dentre os quais se incluem as amarras de aço e seus acessórios [1].

Recebido em 24/10/2012. Texto final em 09/04/2013.
Para dar suporte aos requisitos severos desta aplicação, existem regras específicas para os materiais adequados [2,3], com definição de requisitos extremamente complexos, visto haver na maior parte dos casos a necessidade de se associar elevadas resistências mecânicas com um alto padrão de tenacidade ao impacto.

A Tabela 1 [3] mostra as propriedades mecânicas especificadas para os diversos graus de aços utilizados para os equipamentos de ancoragem para plataformas, de acordo com a "International Association of Classification Societies" (IACS), que unificou os requisitos de todas as Sociedades Classificadoras Navais para estes equipamentos, com destaque para o aço grau R4, com ampla utilização nestas amarras e acessórios de ancoragem, nos dias atuais. 
Tabela 1. Propriedades mecânicas dos aços segundo a norma IACS W22 [3].

\begin{tabular}{c|c|c|c|c|c}
\hline Grau & LE (MPa) & LR $(\mathrm{MPa})$ & $\mathrm{Al}(\%)$ & $\mathrm{RA}(\%)$ & $\mathrm{E}_{\mathrm{cv}} \mathrm{à}-20^{\circ} \mathrm{C}(\mathrm{J})$ \\
\hline R3 & 410 & 690 & 17 & 50 & 40 \\
\hline R3S & 490 & 770 & 15 & 50 & 45 \\
\hline R4 & 580 & 860 & 12 & 50 & 50 \\
\hline R4S & 700 & 960 & 12 & 50 & 56 \\
\hline R5 & 760 & 1000 & 12 & 50 & 58 \\
\hline
\end{tabular}

Nota: LE - limite de escoamento; LR - limite de resistência; Al -alongamento; $\mathrm{RA}$ - redução de área; $\mathrm{E}_{\mathrm{cv}}$ - energia Charpy-V.

Tabela 2. Resultados de propriedades mecânicas obtidas de metais de solda no programa de pesquisa [17-20].

\begin{tabular}{|c|c|c|c|c|c|}
\hline Metal de solda & \multicolumn{2}{|l|}{ Composição química } & Condição & $\mathrm{LR}(\mathrm{MPa})$ & $\operatorname{Ecv}\left(-20^{\circ} \mathrm{C}\right)$ \\
\hline \multirow{2}{*}{1} & \multirow{2}{*}{ C-0,08,Si-0,23,Mn-2,43,Mo-0,49, } & \multirow{2}{*}{ Ni-2,11, Cr- $, 0,29$} & $\mathrm{CS}$ & 881 & 50,5 \\
\hline & & & TTPS & 871 & 57,7 \\
\hline \multirow{2}{*}{2} & \multirow{2}{*}{ C-0,07,Si-0,19,Mn-1,79,Mo-0,35, } & \multirow{2}{*}{$\mathrm{Ni}-2,74, \mathrm{Cr}-0,35$} & $\mathrm{CS}$ & 816 & 78,7 \\
\hline & & & TTPS & 812 & 88,5 \\
\hline \multirow[b]{2}{*}{3} & \multirow{2}{*}{ C-0,048,Si-0,16,Mn-1,46,Mo-0,73, } & \multirow{2}{*}{$\mathrm{Ni}-3,00, \mathrm{Cr}-0,52$} & $\mathrm{CS}$ & 804 & 64,5 \\
\hline & & & TTPS & 794 & 71,0 \\
\hline \multirow{2}{*}{4} & \multirow{2}{*}{ C-0,040,Si-0,16,Mn-2,16,Mo-0,54, } & \multirow{2}{*}{$\mathrm{Ni}-2,95, \mathrm{Cr}-0,31$} & $\mathrm{CS}$ & 847 & 61,6 \\
\hline & & & TTPS & 854 & 61,3 \\
\hline \multirow[b]{2}{*}{5} & \multirow{2}{*}{ C-0,05,Si-0,11,Mn-1,14,Mo-0,54, } & \multirow{2}{*}{$\mathrm{Ni}-2,76, \mathrm{Cr}-, 0,36$} & $\mathrm{CS}$ & 781 & 79,2 \\
\hline & & & TTPS & 862 & 49,7 \\
\hline \multirow{2}{*}{6} & \multirow{2}{*}{\multicolumn{2}{|c|}{ C-0,074,Si-0,44,Mn-1,41,Mo-0,45, Ni-2,03, Cr- $, 0,83$}} & $\mathrm{CS}$ & 942 & 78,7 \\
\hline & & & TTPS & 941 & 48,5 \\
\hline \multirow{2}{*}{7} & \multirow{2}{*}{ C-0,06,Si-0,28,Mn-1,98, Mo-0,41, } & \multirow{2}{*}{$\mathrm{Ni}-2,66, \mathrm{Cr}-, 0,44$} & $\mathrm{CS}$ & 967 & 84,8 \\
\hline & & & TTPS & 984 & 74,0 \\
\hline \multirow{2}{*}{8} & \multirow{2}{*}{ C-0,05,Si-0,14,Mn-1,90,Mo-0,39, } & \multirow{2}{*}{$\mathrm{Ni}-2,97, \mathrm{Cr}-, 0,26$} & $\mathrm{CS}$ & 888 & 33,5 \\
\hline & & & TTPS & 844 & 67,2 \\
\hline Mínimo R4 [3] & Metal Base & & - & 860 & 50,0 \\
\hline Mínimo R4 [3] & Metal de solda & & - & 860 & 36,0 \\
\hline
\end{tabular}

Nota: CS - Como Soldado; TTPS - Tratamento Térmico Pós- Soldagem; $E_{c v}$ - Energia Charpy-V,

LR - Limite de Resistência a Tração.

Tabela 3. Composição química do consumível utilizado (\% em peso).

\begin{tabular}{c|c|c|c|c|c|c|c|c|c|c}
\hline Elemento(\% Peso) & $\mathrm{C}$ & $\mathrm{Si}$ & $\mathrm{P}$ & $\mathrm{S}$ & $\mathrm{Mn}$ & $\mathrm{Mo}$ & $\mathrm{Ni}$ & $\mathrm{Cr}$ & $\mathrm{Cu}$ & $\mathrm{V}$ \\
\hline$(\%$ Peso $)$ & 0,06 & 0,24 & 0,007 & 0,008 & 1,89 & 0,58 & 2,95 & 0,46 & 0,02 & 0,02 \\
\hline
\end{tabular}

Este nível de exigência de propriedades mecânicas, torna a soldagem destes componentes um grande desafio em termos não somente da definição do procedimento de soldagem mais adequado, como, principalmente na seleção e/ou desenvolvimento de consumíveis adequados para a aplicação.

É importante ressaltar que nestes casos, mesmo as normas de qualificação de consumíveis de soldagem, tais como AWS A 5.5 [4] e MIL-E-22200/1F [5], ainda não definem os critérios de aprovação de consumíveis para esta aplicação, visto que estas normas limitam-se à consumíveis com resistência máxima de $120 \mathrm{ksi}(830 \mathrm{MPa})$, portanto insuficiente para atendimento dos requisitos de aços como o grau R4, isto é, $860 \mathrm{MPa}$ de tensão limite de resistência. Adicionalmente, deve-se ressaltar que, existe ainda um outro complicador, visto que, mesmo as propriedades quando especificadas, são relativas ao metal de solda no estado de como soldado, não havendo menção à manutenção de propriedades quando se faz necessária a realização de tratamento térmico de alívio de tensões, tratamento mandatório para acessórios de ancoragem, devido à necessidade de alívio de tensões residuais destes componentes que operam em condição severas de carregamento[6,7].

Portanto, para atender os requisitos de projetos específicos de soldagem destes aços, utiliza-se o procedimento alternativo de qualificação de lotes de consumíveis em atendimento das propriedades do próprio metal base na condição de tratado termicamente.

Considerando este aspecto de impossibilidade de garantia de fornecimento de consumíveis com as propriedades requeridas com garantia de norma específica, é fundamental um estudo criterioso e investigativo para avaliar a adequação de consumíveis especiais disponíveis no mercado, de forma a avaliar a possível adequação de algum destes à aplicação em questão. Neste 
aspecto, cabe destacar que os poucos estudos disponíveis na literatura envolvendo metais de solda com resistência mecânica da ordem de $860 \mathrm{MPa}$ ou superior [8-16], embora de relevância do ponto de vista de análise de composição química e evolução microestrutural, também não abordaram o efeito de tratamentos térmicos pós-soldagem nas propriedades mecânicas dos metais de solda de extra alta resistência.

Com base nestas evidências, foi realizada uma série de estudos envolvendo diversos consumíveis com diferentes composições químicas, o que permitiu a obtenção dos resultados mostrados na Tabela 2 [17-20], onde se nota que o metal de solda número 7 foi aquele que obteve o melhor resultado de resistência e tenacidade ao impacto após tratamento térmico pós-soldagem.

O principal objetivo deste trabalho é realizar uma avaliação detalhada e complementar das propriedades de metal de solda obtido do consumível de soldagem que apresentou o melhor resultado dentre os consumíveis avaliados nestes trabalhos anteriores [17-20], para atendimento dos requisitos do aço grau R4 após a realização de tratamento térmico pós-soldagem, de forma a investigar a influência deste tratamento nas propriedades mecânicas do metal de solda e , consequentemente, a viabilidade da utilização deste mesmo consumível para a soldagem segura de componentes de ancoragem fabricados em aços da classe R4.

\section{Materiais e Métodos}

\subsection{Materiais}

Realizou-se o estudo com um eletrodo revestido comercial de 4,0mm de diâmetro, cuja composição química, conforme informações do fabricante, é apresentada na Tabela 3.

\subsection{Soldagem dos Corpos-de-Prova}

As juntas foram soldadas a partir de chapas com $19 \mathrm{~mm}$ de espessura e $700 \mathrm{~mm}$ de comprimento. A geometria e demais dimensões da junta são apresentadas na Figura 1. As juntas foram preaquecidas às temperaturas de 200 e $250^{\circ} \mathrm{C}$, através de chama oxiacetilênica e o controle, tanto do preaquecimento quanto da temperatura interpasses foi realizada através de pirômetro de contato, devidamente calibrado.

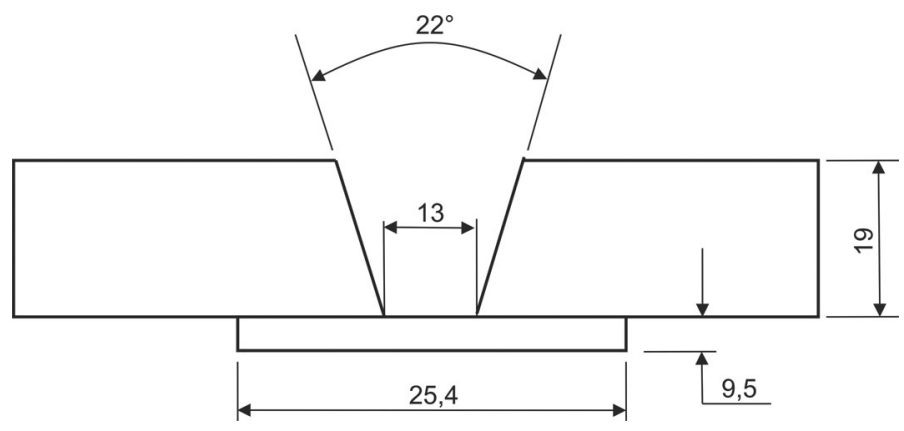

Figura 1. Detalhes da geometria da junta utilizada. Cotas em $\mathrm{mm}$.

A Tabela 4 apresenta o conjunto de parâmetros médios utilizados para a soldagem, enquanto a Figura 2 mostra a seqüência de deposição dos passes de soldagem.

Tabela 4. Parâmetros de soldagem utilizados

\begin{tabular}{c|c|c|c|c}
\hline $\begin{array}{c}\Phi \\
(\mathrm{mm})\end{array}$ & $\begin{array}{c}\text { Corrente } \\
(\mathrm{A})\end{array}$ & $\begin{array}{c}\text { Tensão } \\
(\mathrm{V})\end{array}$ & $\begin{array}{c}\text { AT } \\
(\mathrm{kJ} / \mathrm{mm})\end{array}$ & $\begin{array}{c}\text { Número de } \\
\text { passes }\end{array}$ \\
\hline 4,0 & $185-195$ & $23-28$ & 1,80 & 18 \\
\hline
\end{tabular}

Nota: $\Phi$ - diâmetro do eletrodo; $A T$-aporte térmico.

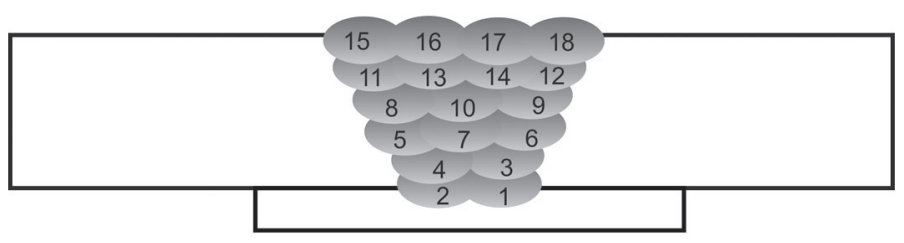

Figura 2. Seqüência de deposição dos passes de soldagem.

\subsection{Tratamentos Térmicos Pós Soldagem (TTPS)}

Foram realizados tratamentos térmicos consistindo de aquecimento a $600^{\circ} \mathrm{C}$ por 2 horas, sendo esta condição comparada à condição da junta de como soldada.

Os TTPS foram realizados através de equipamentos projetados especificamente para esta finalidade, com aquecimento por resistência elétrica, isolamento com manta térmica e controle de temperatura através de termopares, devidamente calibrados. Utilizou-se taxas de aquecimento e resfriamento controladas de $200^{\circ} \mathrm{C}$ por hora.

\subsection{Ensaios Mecânicos}

Foram removidos corpos-de-prova longitudinais e transversais ao cordão de solda para ensaios de tração, de impacto Charpy-V e dureza.

Os ensaios de tração foram realizados à temperatura ambiente, em corpos-de-prova retirados longitudinalmente ao cordão de solda, para avaliação de todas as propriedades de tração do metal de solda.

Foram realizados ensaios de impacto Charpy- $\mathrm{V}$ nas temperaturas de: $-60 ;-40 ;-20 ; 0$ e $20^{\circ} \mathrm{C}$, tanto na condição de como soldado quanto após tratamento térmico, visando avaliar a segurança na variação da tenacidade para utilização do consumível. Os ensaios foram realizados em corpos-deprova normalizados conforme a norma ASTM A-370 [21] nas dimensões de $(10 \times 10 \times 55 \mathrm{~mm})$ e retirados transversalmente ao cordão de solda, a $2 \mathrm{~mm}$ da superfície da junta. $\mathrm{O}$ entalhe foi posicionado no plano da espessura e no centro do cordão de solda.

Foram realizados ensaios de dureza Vickers com aplicação de carga de 10 kgf em corpos-de-prova transversais ao cordão de solda, sendo realizada uma varredura de dureza da superfície até a raiz do metal de solda.

\subsection{Ensaios Metalográficos}

Foram realizados ensaios metalográficos por microscopia 
eletrônica de varredura (MEV) nos metais de solda, para avaliação das microestruturas.

A preparação para análise consistiu de procedimento convencional de lixamento e polimento seguido de ataque químico com o reagente nital $2 \%$.

\section{Resultados}

\subsection{Análise química}

A Tabela 5 mostra a composição química dos metais depositados, onde se pode destacar os teores de $\mathrm{Mn}$ e Ni, além do elevado carbono equivalente.

\subsection{Ensaio de tração}

A Tabela 6 mostra os resultados dos ensaios de tração, realizados nos metais de solda, onde se notam as seguintes características principais:

a) Todos os valores de propriedades do ensaio de tração apresentaram-se acima do requisito mínimo para o aço grau R4;

b) Tanto o limite de escoamento quanto o limite de resistência apresentaram uma diminuição da ordem de $10 \%$ devido ao aumento do preaquecimento;

c) O TTPS não propiciou mudanças nas propriedades mecânicas.

\subsection{Ensaio de impacto Charpy-V}

A Tabela 7 e Figura 3 mostram os resultados dos ensaios de impacto realizados nos metais de solda, onde se notam as seguintes características principais:

a) Os valores de tenacidade ao impacto apresentaram pouca variação para as diferentes condições de análise;

b) Todos os valores obtidos foram superiores ao requisito mínimo para o aço grau R4 e;

c) As curvas de transição evidenciam que foi possível obter valores de tenacidade ao impacto superiores ao mínimo requerido para o aço $\mathrm{R} 4 \mathrm{em}$ toda a faixa de temperaturas avaliada, tanto na condição de como soldado quanto após TTPS.

Tabela 5. Composição química dos metais depositados (\%peso).

\begin{tabular}{c|c|c|c|c|c|c|c|c|c|c|c}
\hline Elemento & $\mathrm{C}$ & $\mathrm{Si}$ & $\mathrm{P}$ & $\mathrm{S}$ & $\mathrm{Mn}$ & $\mathrm{Mo}$ & $\mathrm{Ni}$ & $\mathrm{Cr}$ & $\mathrm{Cu}$ & $\mathrm{V}$ & $\mathrm{Ceq}(*)$ \\
\hline \% Peso & 0,065 & 0,282 & 0,0105 & $<0,008$ & 1,978 & 0,412 & 2,661 & 0,435 & 0,010 & 0,025 & 0,748 \\
\hline
\end{tabular}

$(*) \mathrm{Ceq}=\mathrm{C}+\mathrm{Mn} / 6+(\mathrm{Cr}+\mathrm{Mo}+\mathrm{V}) / 5+(\mathrm{Cu}+\mathrm{Ni}) / 15[22]$

Tabela 6. Resultados dos ensaios de tração dos metais de solda.

\begin{tabular}{c|c|c|c|c|c}
\hline \multirow{2}{*}{ Metal de Solda } & Condição & LE(MPa) & LR(MPa) & Al(\%) & RA(\%) \\
\hline \multirow{2}{*}{ M200 } & CS & 875 & 967 & 21,4 & 62,9 \\
\cline { 2 - 6 } & TTPS & 892 & 984 & 21,4 & 61,5 \\
\hline \multirow{2}{*}{ M250 } & CS & 796 & 892 & 21,1 & 63,2 \\
\cline { 2 - 6 } & TTPS & 772 & 900 & 22,3 & 63,2 \\
\hline & Mínimo R4 [3] & 580 & 860 & 12,0 & 50,0 \\
\hline
\end{tabular}

Nota: CS- como soldado; TTPS- Tratamento Térmico Pós-Soldagem

Tabela 7. Resultados dos ensaios de impacto à $-20^{\circ} \mathrm{C}$ (Joules).

\begin{tabular}{c|c|c|c|c|c}
\hline \multirow{2}{*}{ Metal de Solda } & Condição & $1^{\circ}$ ensaio & $2^{\circ}$ ensaio & $3^{\text {o ensaio }}$ & Média \\
\hline \multirow{2}{*}{ M200 } & CS & 97,0 & 95,0 & 86,0 & 92,7 \\
\cline { 2 - 6 } & TTPS & 84,0 & 85,0 & 98,0 & 89,0 \\
\hline \multirow{2}{*}{ M250 } & CS & 90,5 & 89,5 & 107,5 & 95,8 \\
\cline { 2 - 6 } & TTPS & 99,0 & 93,5 & 101,0 & 97,8 \\
\hline Mínimo R4 [3] & Metal base & & & & 50,0 \\
\hline Mínimo R4 [3] & Metal de solda & & & & 36,0 \\
\hline
\end{tabular}

Nota: CS - Como Soldado; TTPS - Tratamento Térmico Pós-Soldagem 


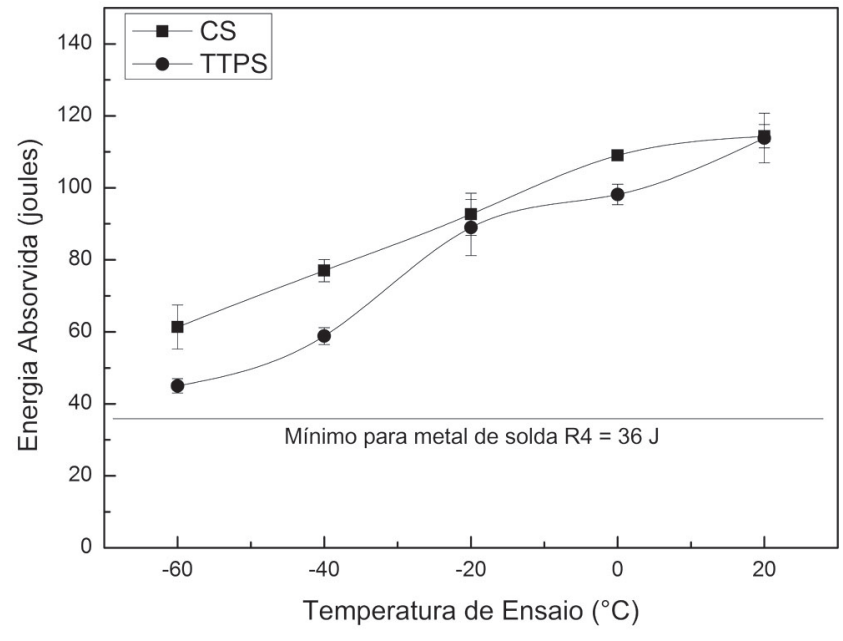

M200

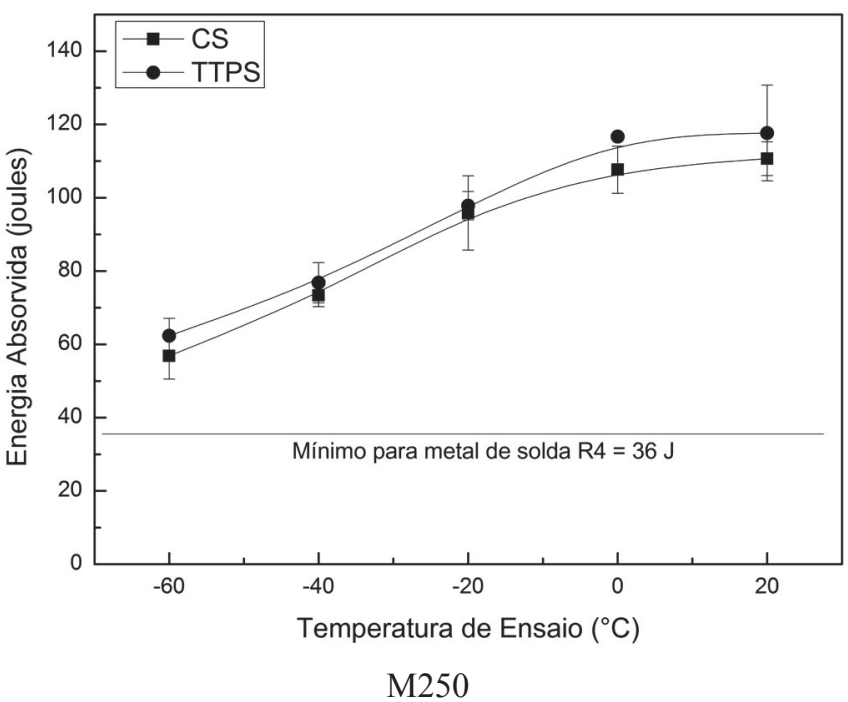

M250

Figura 3. Variação da energia absorvida dos metais de solda com a temperatura de ensaio.

\subsection{Ensaio de dureza Vickers}

A Figura 4 mostra os resultados dos ensaios de dureza Vickers (perfil), realizados nos metais de solda. Os valores apresentados correspondem ao resultado de uma identação por posição, onde se notam as seguintes características principais:

a) Os maiores valores de dureza foram observados na região próxima da superfície dos metais de solda, onde se verificou valores da ordem de $350 \mathrm{HV}_{10}$;

b) A medida que se afasta da superfície, foram verificados valores inferiores de dureza em todas as condições;

c) O metal de solda M200 propiciou valores de dureza superiores aos do metal de solda M250, tanto na condição de como soldado quanto após TTPS e;

d) O TTPS promoveu uma redução nos valores de dureza, principalmente, na região próxima da superfície dos metais de solda.

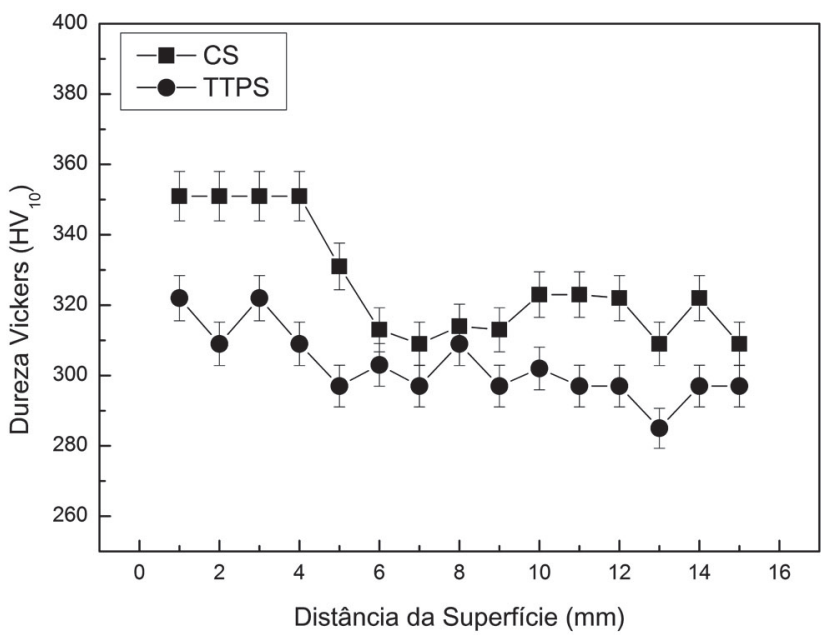

M200

\subsection{Ensaios Metalográficos}

As Figuras 5 e 6 mostram as micrografias dos metais de solda obtidos para as diferentes condições, quando observados por microscopia eletrônica de varredura (MEV), onde se notam as seguintes características:

a) Na região colunar do último passe ("Top Bead" (TB)), notase a predominância de microestrutura martensítica para ambas as condições e;

b) Na região do entalhe dos corpos-de-prova Charpy-V, foi possível verificar que a microestrutura é composta por martensita e bainita revenida, com predominância deste último constituinte, tanto na região colunar (RC) quanto na região reaquecida (RR), em todas as condições de análise.

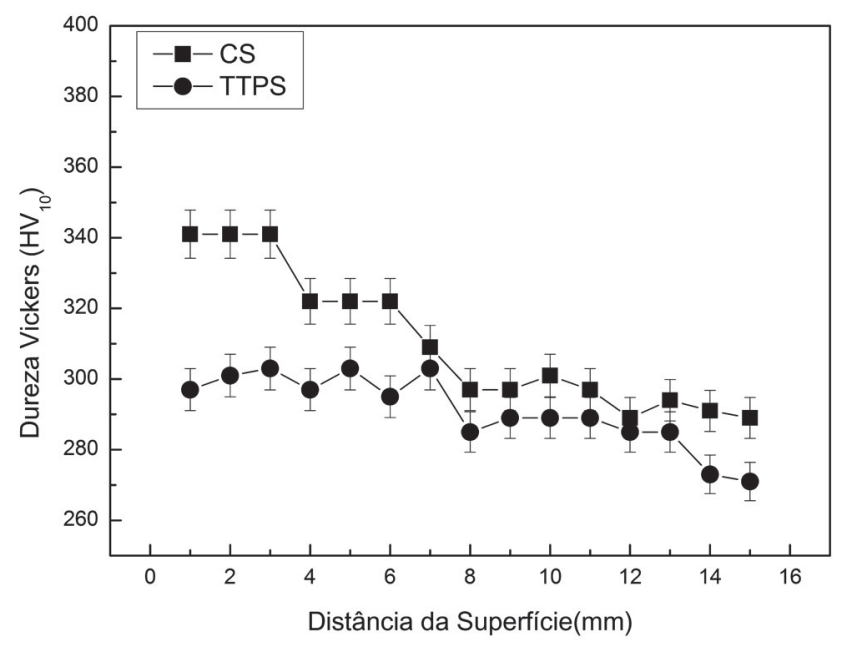

M250

Figura 4. Resultados dos ensaios de dureza Vickers $\left(\mathrm{HV}_{10}\right)$. 


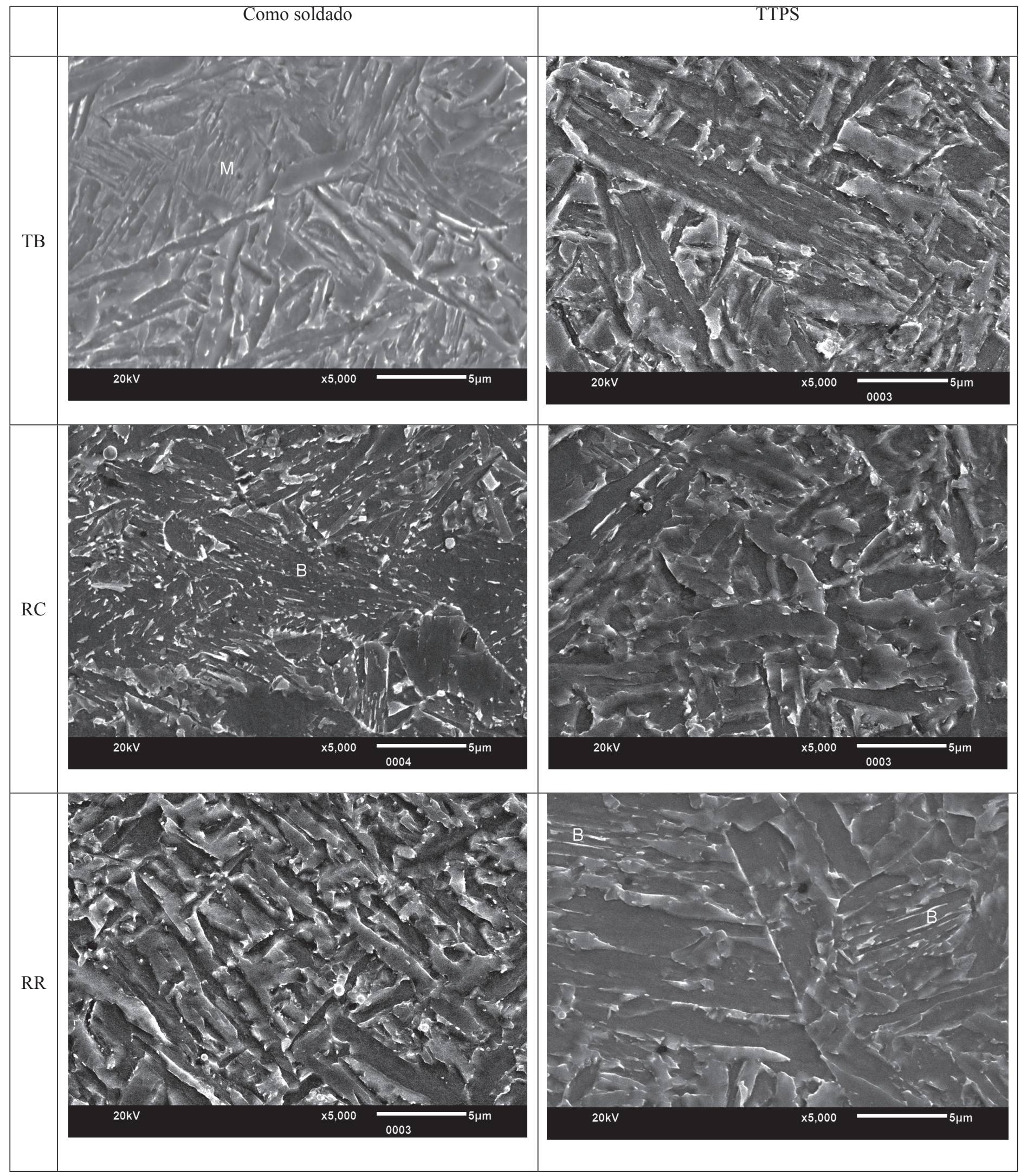

Figura 5. Aspecto microestrutural do metal de solda M200 observado por MEV. Ataque: nital 2\%. 


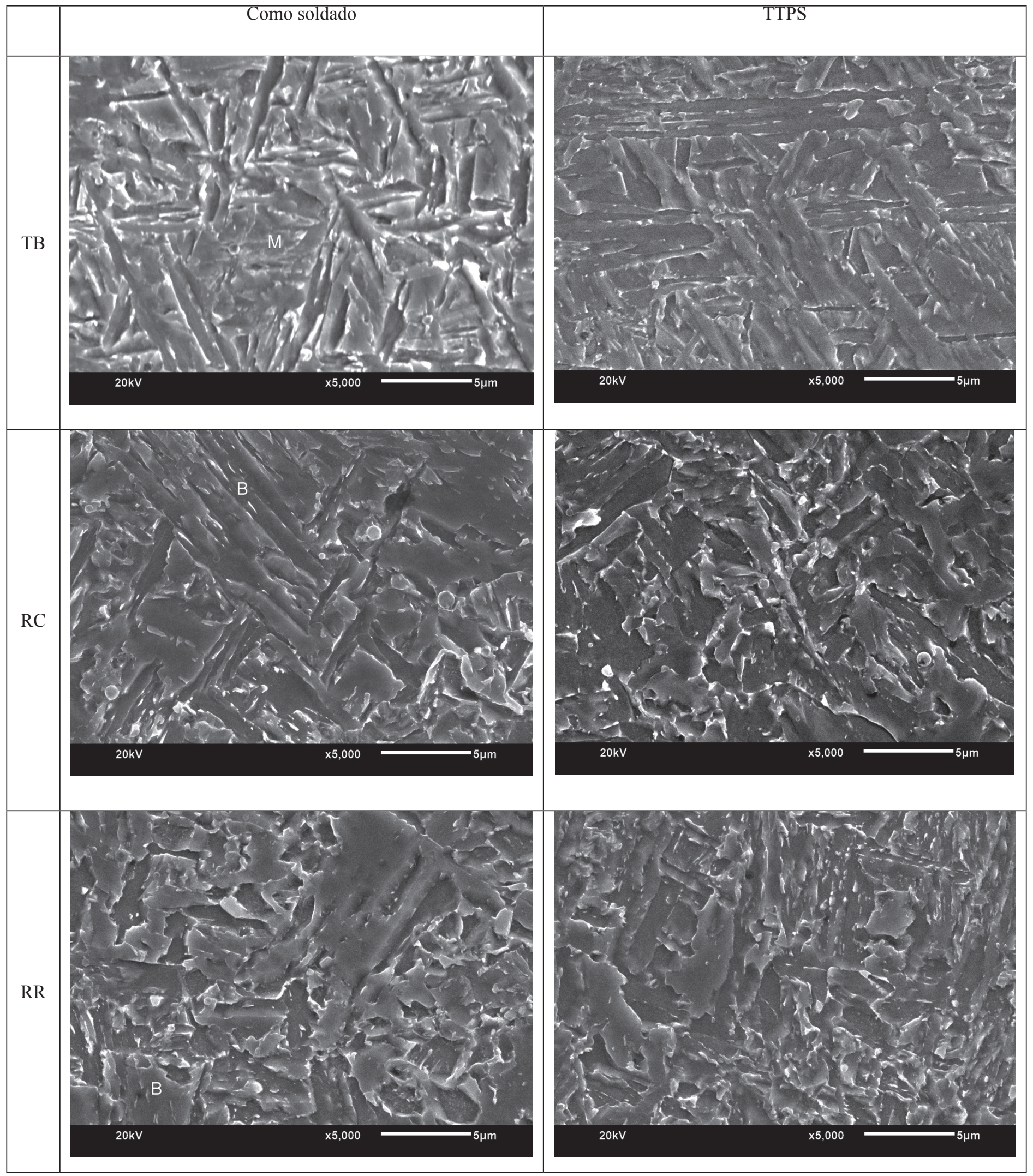

Figura 6. Aspecto microestrutural do metal de solda M250 observado por MEV. Ataque: nital 2\%. 


\section{Discussão}

\subsection{Propriedades Mecânicas}

A Tabela 6 mostra os resultados de resistência mecânica para as diversas condições de análise, onde se verifica que todos os resultados se apresentaram acima do patamar de $860 \mathrm{MPa}$. Isto é um fato extremamente relevante, já que, como abordado pela literatura $[10,11]$, a obtenção de valores elevados de resistência mecânica para os consumíveis de maior resistência tem sido o foco de preocupação maior. De fato, Surian et al. [11,23,24] ressaltam, inclusive, que em alguns casos, é importante o controle do aporte térmico para a obtenção da resistência requerida, situação também observada por Jorge et al [17]. Nos estudos realizados previamente [17-20], identificou-se que este parâmetro é um ponto crítico a ser superado como evidenciado na Tabela 2. Nota-se nesta tabela, que o limite de resistência esteve sempre em patamares inferiores ou muito próximos ao limite de 860MPa, não propiciando condições de comportamento seguro dos consumíveis utilizados, quando se considera as variações normais que podem acontecer em consequência de diferentes corridas de um mesmo consumível, alterações de soldador, de posição de soldagem ou mudança de metal base [10].

Segundo Ramirez [10] e Surian et al. [11], uma forma de se ter uma estimativa da resistência mecânica do metal de solda de alta resistência é através do controle do carbono equivalente deste metal de solda. No entanto, esta afirmação deve ser vista apenas do ponto de vista qualitativo, quando se opera com metais de solda de alta e extra alta resistência, dado o elevado grau de dispersão de resultados que os diversos metais de solda podem gerar, em função do efeito interativo dos diversos elementos de liga atuantes em metais de solda de alta resistência, ainda não completamente entendidos. De fato, a Figura 7 mostra uma coletânea de resultados de diversos autores [8,10,11,18-20], onde se verifica que a dispersão de resultados se acentua para maiores valores de carbono equivalente, o que inviabiliza uma extrapolação segura de resultados com base em outros resultados experimentais.

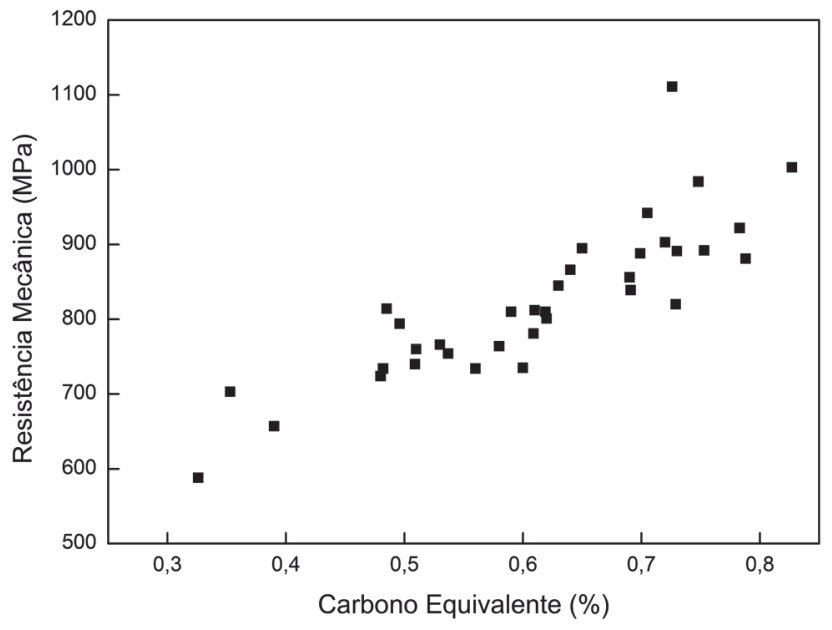

Figura 7. Relação entre a resistência mecânica e o carbono equivalente para metais de solda obtidos por diversos autores $[8,10,11,18-20]$.
Este elevado grau de dispersão, pode estar associado com modificações microestruturais significativas. De fato, segundo Ramirez [25], para valores de carbono equivalente superiores a 0,47 , começa a predominar produtos de baixa temperatura de transformação, incluindo a martensita. Por outro lado, Lord et al.[8] afirmam que para a faixa de velocidades de resfriamento normais de soldagem, não se tem temperabilidade suficiente para formação somente de martensita, sendo a microestrutura do metal de solda de alta resistência uma mistura de martensita e bainita. Já Svensson [9] afirma que metais de solda com limite de escoamento superiores a 690MPa apresentam uma microestrutura constituída de ferrita acicular, martensita e bainita. Concordante com estas argumentações, Karlsson et al. [12] comentam que as microestruturas de metais de solda de alta resistência contendo de 2 a $3 \% \mathrm{Ni}$, são constituídas de ferrita acicular, martensita e bainita, e dependendo do percentual de cada um destes constituintes haverá mudança nas propriedades mecânicas do metal de solda. Logo, nesta faixa de composição química, não é surpreendente que a velocidade de resfriamento tenha uma forte influência nas propriedades mecânicas.

Todas estas evidências, reforçam a necessidade de se procurar um consumível que propicie um metal de solda com propriedades de tração superiores às encontradas na Tabela 2, de forma que todas estas variações sejam consideradas quando da qualificação de um procedimento de soldagem. Assim, o metal de solda que atende a estas características é justamente aquele utilizado no presente trabalho, visto que o metal de solda número 6, que também apresentou comportamento interessante, sob o ponto de vista de limite de resistência, não teve o mesmo comportamento quanto a tenacidade ao impacto após o tratamento térmico póssoldagem.

Neste aspecto, é importante citar que algumas publicações $[8,12,14]$ utilizando consumíveis com composição química básica (C-0,05, Mn-2,0, Si-0,30, Cr-0,40, Mo-0,60, Ni-3,0) similar à do presente estudo, tem mostrado que as propriedades são mantidas dentro de um mesmo patamar independente das condições de soldagem. De fato, a Tabela 8 mostra um resumo dos resultados obtidos nestes estudos $[8,12,14]$ onde se evidencia que a resistência mecânica apresentou uma variação muito pequena para as diversas condições experimentais (apenas 8\%), sendo a mudança mais significativa no limite de escoamento, o qual no entanto, apresenta-se em patamares superiores aos requisitos do aço $\mathrm{R} 4$. Deve ser ressaltado ainda dentre os resultados mostrados na Tabela 8 , que os valores de energia absorvida no ensaio de impacto, se apresentam em patamares elevados mesmo para a temperatura de $-40^{\circ} \mathrm{C}$.

Os resultados obtidos no presente trabalho, se mostram concordantes com estes dados da literatura [8,12,14], tanto para a resistência mecânica quanto para a tenacidade ao impacto.

Em relação à tenacidade ao impacto, observa-se ainda que os valores obtidos se mostram uniformes (Tab.7), o que pode ser atribuído à microestrutura existente. De fato, a observação das microestruturas das regiões colunar e reaquecida para ambos os preaquecimentos (Figs. 5 e 6), permite inferir pela uniformidade da mesma nestas regiões. A maior diferença na microestrutura observada está justamente na região colunar do último passe 
Tabela 8. Propriedades Mecânicas obtidas com o consumível de soldagem similar ao do presente estudo para diversas condições experimentais $[8,12,14]$.

\begin{tabular}{c|c|c|c|c|c|c|c|c|c|c}
\hline Solda Nr. & $\begin{array}{c}1 \\
{[12]}\end{array}$ & $\begin{array}{c}2 \\
{[12]}\end{array}$ & $\begin{array}{c}3 \\
{[12]}\end{array}$ & $\begin{array}{c}4 \\
{[12]}\end{array}$ & $\begin{array}{c}5 \\
{[12]}\end{array}$ & $\begin{array}{c}6 \\
{[12]}\end{array}$ & $\begin{array}{c}7 \\
{[12]}\end{array}$ & $\begin{array}{c}8 \\
{[12]}\end{array}$ & $\begin{array}{c}9 \\
{[8]}\end{array}$ & $\begin{array}{c}10 \\
{[14]}\end{array}$ \\
\hline Temp. Interpasses $\left({ }^{\circ} \mathrm{C}\right)$ & 125 & 150 & 200 & 200 & 200 & 125 & 200 & 250 & 250 & 250 \\
\hline $\mathrm{AT}(\mathrm{kJ} / \mathrm{mm})$ & 1,4 & 1,3 & 1,1 & 1,3 & 1,3 & 1,8 & 1,7 & 1,7 & 1,0 & 1,4 \\
\hline $\mathrm{LE}(\mathrm{MPa})$ & 978 & 885 & 922 & 885 & 844 & 939 & 858 & 734 & 872 & 756 \\
\hline $\mathrm{LR}(\mathrm{MPa})$ & 994 & 942 & 953 & 929 & 938 & 972 & 931 & 924 & 922 & 945 \\
\hline $\mathrm{Ecv}\left(+20^{\circ} \mathrm{C}\right)$ & 86 & 101 & 94 & 105 & 104 & 84 & 87 & 88 & 102 & 80 \\
\hline $\mathrm{Ecv}\left(-40^{\circ} \mathrm{C}\right)$ & 74 & 87 & 77 & 64 & 78 & 77 & 74 & 50 & 79 & 50 \\
\hline
\end{tabular}

Nota: $E_{c v}$ - Energia Charpy- $V$.

(TB), a qual, no entanto, não contribui para a tenacidade ao impacto, por não fazer parte do corpo-de-prova Charpy-V.

Esta mesma evidência também é notada nos resultados dos ensaios de dureza Vickers (Fig.4), onde se percebe uma queda da dureza da região próxima da superfície para o resto da junta soldada, com estabilização desta propriedade para o restante da espessura.

\subsection{Efeito do tratamento térmico pós-soldagem}

Muitos são os estudos sobre metais de solda de alta resistência, como já citado anteriormente, os quais fazem avaliações importantes sobre o efeito da composição química na microestrutura e nas propriedades mecânicas. Contudo, raramente são disponíveis publicações envolvendo o efeito de tratamentos térmicos pós-soldagem nestes metais de solda. As publicações que abordam este assunto normalmente estão estudando o efeito de algum elemento em particular [26-33], não considerando composições ricas em diversos elementos de liga e, consequentemente, o efeito sinérgico entre estes elementos. Outros trabalhos [34-36] que abordam este tipo de composição, não envolvem metais de solda com resistência mecânica da ordem de $860 \mathrm{MPa}$, como a estudada no caso presente. Desta forma, o presente trabalho visa contribuir neste aspecto ao realizar uma análise do efeito do TTPS nas propriedades mecânicas do metal de solda de extra alta resistência, principalmente, pelo fato que dos resultados prévios terem registrado o efeito complexo deste procedimento nestas propriedades.

A maioria dos trabalhos que envolvem o efeito do TTPS na resistência mecânica [6,17-20,26-40], relatam uma queda desta propriedade com a execução do TTPS. No entanto, deve-se destacar que no caso de metais de solda de mais alta resistência, existe uma tendência para que a diferença seja cada vez mais reduzida [18-20], o que provavelmente está associado com o fato da microestrutura da região reaquecida apresentar a mesma microestrutura da região colunar, o que interfere na composição percentual da resistência do corpo-de-prova utilizado para o ensaio de tração representativo da qualificação do metal de solda $[9,25]$. Isto também foi verificado para os metais de solda dos estudos realizados, pois a consulta à Tabela 2 mostra a pequena diferença para a resistência mecânica para os diversos resultados obtidos entre as condições de como soldado e após TTPS. De fato, a observação dos resultados apresentados na Tabela 2, permite inferir que a maior diferença observada foi da ordem de $10 \%$ em um único caso, sendo que na maioria dos casos o valor de ocorrência foi da ordem de $1 \%$ de variação.

No caso específico do metal de solda em estudo (Tab.6), as diferenças foram similares à esta, também da ordem de $1 \%$, para ambos os casos. É de se destacar ainda que, de igual importância, por estudos realizados envolvendo a variação do tempo de tratamento térmico na resistência mecânica [18], não se evidenciou variações significativas também nesta questão (Fig.8). Nota-se nesta figura que a maior diferença na resistência mecânica é devido à diferença no preaquecimento, ratificando a discussão do item anterior.

A execução de tratamentos térmicos pós-soldagem tende a produzir mudanças microestruturais que afetam a tenacidade, podendo em alguns casos melhorá-la e em outros casos fragilizar, sendo este efeito muito dependente da composição química e da microestrutura do metal de solda no estado como soldado.

A análise microestrutural conduzida por microscopia eletrônica (Figs. 5 e 6), permitiu evidenciar a ocorrência predominante de microestrutura martensítica na região do último passe e banita na região da ponta do entalhe Charpy-V, com morfologia similar para ambos os metais de solda.

Estas evidências microestruturais apresentam relevância, pois mostram que a ocorrência de microestrutura similar é a razão pela qual a tenacidade do metal de solda apresenta a mesma tenacidade para todas as condições experimentais realizadas no presente trabalho.

Assim como no caso dos resultados de resistência mecânica (Fig.8), foi possível observar comportamento similar para a tenacidade ao impacto, em relação à variação do tempo de tratamento térmico, conforme mostra a Figura 9, evidenciando não somente uma uniformidade importante dos resultados, mas também uma proximidade dos valores para as condições experimentais utilizadas. 


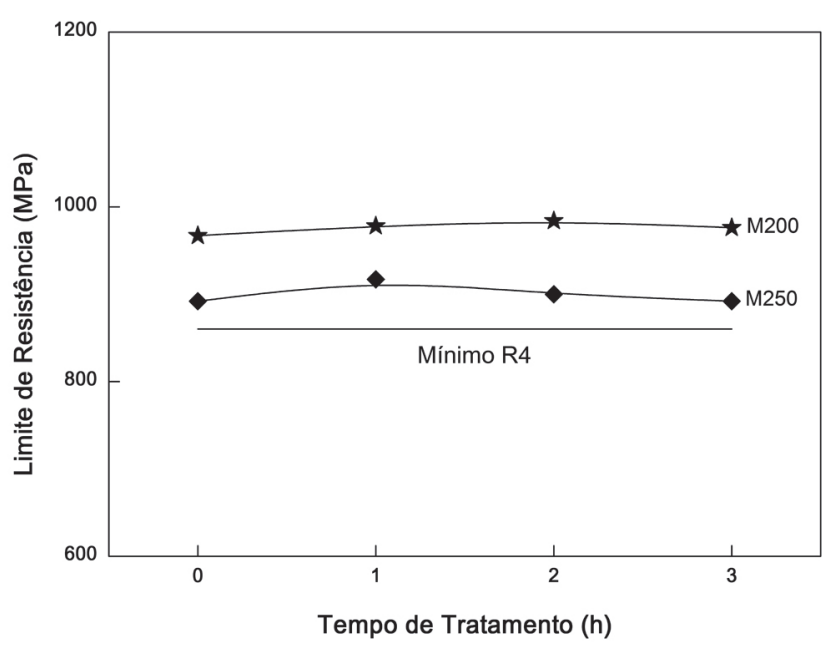

Figura 8. Efeito do tempo de TTPS na resistência mecânica do metal de solda [18].

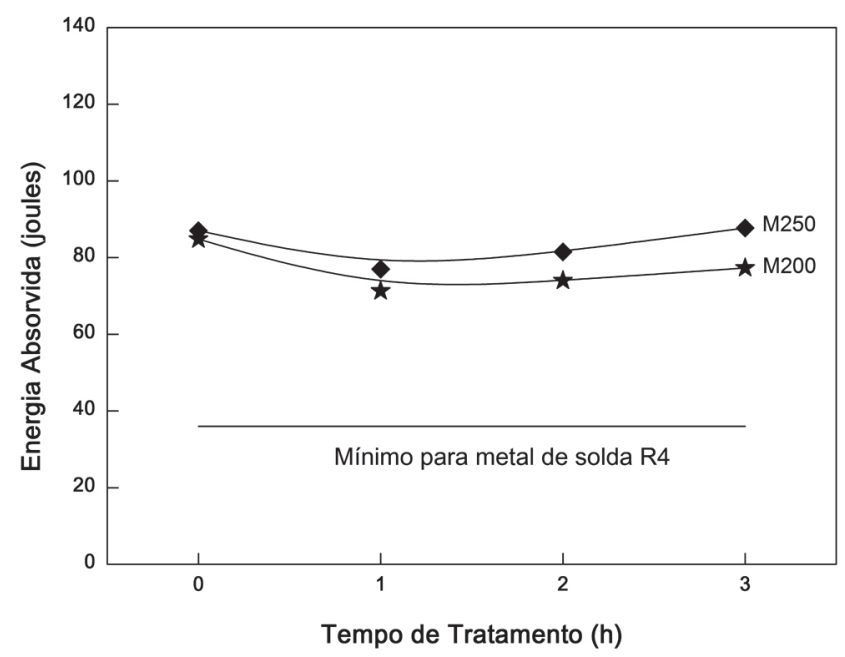

Figura 9. Efeito do tempo de TTPS na tenacidade ao impacto do metal de solda [18].

\subsection{Considerações Adicionais}

Os resultados apresentados no presente trabalho tiveram como objetivo, consolidar uma série de evidências experimentais envolvendo o estudo de metais de solda de alta resistência para soldagem de aço grau R4 [3], o qual apresenta requisitos desafiadores de resistência e tenacidade ao impacto de $860 \mathrm{MPa}$ e 50 Joules à $-20^{\circ} \mathrm{C}$, respectivamente.

Como já comentado, no caso presente, a necessidade de realização de tratamento térmico pós-soldagem para alívio das tensões residuais, mandatória nos projetos em questão, aumenta o grau de dificuldade de obtenção das propriedades desejadas.

Embora outros autores já tenham apresentado estudos com composição química similar [8,12,14], observou-se que em nenhuma destas pesquisas foi avaliado o efeito do TTPS nas propriedades do metal de solda, o que foi o foco do presente trabalho. Neste aspecto, é importante ressaltar que são muito raras as publicações abordando o efeito do TTPS neste tipo de metal de solda, o que tornou necessária uma análise mais detalhada por microscopia eletrônica de varredura para tentar permitir um melhor entendimento do comportamento das propriedades mecânicas e suprir esta falta de disponibilidade de literatura técnica sobre o assunto.

Os resultados obtidos no presente trabalho propiciaram condições para um conhecimento adequado do metal de solda em estudo e, de maior importância, de sua indicação confortável para soldagem do aço grau R4, visto que, tanto do ponto de vista de resistência quanto de tenacidade ao impacto, foram obtidos resultados superiores aos mínimos exigidos para utilização. Além disso, foi também possível verificar que, mesmo com variações significativas das condições experimentais, o que segundo a literatura $[8,10,11]$ é extremante complexo para a manutenção das propriedades, o comportamento do mesmo pouco se alterou, o que é mais um fator positivo para sua indicação.

A maior diferença de propriedades, da ordem de $10 \%$, encontrada nos limites de resistência e escoamento, foi devida ao preaquecimento, confirmando resultados de trabalhos anteriores $[17,20]$.

Com base em todas as evidências apresentadas, e particularmente, considerando os resultados dos ensaios de tração, o metal de solda em estudo pode ser utilizado na soldagem de aços grau R4 [3], utilizando-se o preaquecimento a $200^{\circ} \mathrm{C}$ e o tratamento térmico pós-soldagem à $600^{\circ} \mathrm{C}$ por 2 horas.

\section{Conclusões}

Do exposto no transcurso do presente trabalho, pode-se concluir que:

a) $\mathrm{O}$ metal de solda estudado mostrou-se adequado para utilização na soldagem do aço grau R4 da norma IACS W22;

b) Todos os resultados de resistência mecânica e de tenacidade ao impacto foram superiores aos mínimos requeridos para o aço grau R4 da norma IACS W22;

c) A tenacidade ao impacto mostrou resultados superiores aos exigidos mesmo para temperaturas da ordem de $-60^{\circ} \mathrm{C}$;

d) $\mathrm{O}$ tratamento térmico pós-soldagem não propiciou modificações na tenacidade ao impacto do metal de solda em estudo.

\section{Agradecimentos}

Os autores agradecem às Instituições pelo apoio prestado na execução do presente trabalho: A Fluke Engenharia Ltda., CEFET/RJ, PUC-Rio, ESAB, CNPq e FINEP.

\section{Referências Bibliográficas}

[1] PAIVA, A.M.C.; Integridade de Sistemas de Ancoragem: contribuições às metodologias de análise, 2000, 125p. , Dissertação de Mestrado, CEFET/RJ, Rio de Janeiro, Brasil, 2000 .

[2] AMERICAN BUREAU OF SHIPPING, Guide for certification of offshore mooring chain, Section 3, Accessories, USA, 1999.

[3] INTERNATIONALASSOCIATION OF CLASSIFICATION 
SOCIETIES, Offshore Mooring Chain, W22, USA, 2011. [4] AMERICAN WELDING SOCIETY, Specification for low alloy steel electrodes for shielded metal arc welding, AWS 5.5, USA, 1996.

[5] MILITARY STANDARDS, Electrodes, welding, mineral covered, iron-powder, low hydrogen medium and high tensile steel, as welded or stress-relieved weld application, MIL 222001F, USA, 1981.

[6] JORGE, J.C.F. et al., Desenvolvimento de procedimento de reparo por soldagem de amarras de aço para ancoragem de plataformas de petróleo - Parte II - Homologação do Procedimento, IN: CONGRESSO NACIONAL DE SOLDAGEM, 28ㅜ, 2002, São Paulo, .Anais...,2002, p. 1-10.

[7] JORGE,J.C.F. et al., Evaluation of the mechanical properties on welded links of high strength steel mooring chains after fatigue testing, IN: CONGRESSO NACIONAL DE SOLDAGEM, 370, 2008, São Paulo, Anais..., 2008, p. 1-10.

[8] LORD, M.; JENNINGS,G. , Effect of interpass temperature on properties of high-strength weld metals, Svetsaren, SWEDEN, v. 54, n.1-2, p.53-58, 1999.

[9] SVENSSON, L.E., Consumables for Welding High Strength Steels, Svetsaren, SWEDEN, v. 54, n.1-2, pp.29-33, 1999.

[10] RAMIREZ, J.E., Examining the Mechanical Properties of High-Strength Steel Weld Metals , Welding Journal, USA, v.88, n.1, p.32-38, Jan., 2009.

[11] SURIAN, E.S. et al., SMAW, FCAW and SAW HighStrength Ferritic Deposits: The Challenge is Tensile Properties, Welding Journal, USA, v. 89, n. 3, p.54-64-s, Mar., 2010.

[12] KARLSSON, L., KEEHAN, E., ANDREN, H.O.; BHADESHIA, H.K.D.H., Development of high strength steel weld metals -potential of novel high-Ni compositions, IN: EUROJOIN, 50, 2004, Vienna, Proceedings.., 2004, p.1-8.

[13] SVENSSON, L.E., Microstructure and properties of high strength weld metals, Materials Science Forum, Switzerland, vol. 539-543, p.3937-3942, Mar., 2007.

[14] KEEHAN, E., L.KARLSOON, L.; ANDREN ,H.O., Influence of $\mathrm{C}, \mathrm{Mn}$ and $\mathrm{Ni}$ contents on microstructure and properties of strong steel weld metals, Part I - Effect of nickel content, Science and Technology of Welding and Joining, UK, v. 11, n. 1, p. 1-8, 2006.

[15] KEEHAN, E., L.KARLSOON, L.; ANDREN ,H.O., Influence of $\mathrm{C}, \mathrm{Mn}$ and $\mathrm{Ni}$ ontents on microstructure and properties of strong steel weld metals, Part II - Impact toughness gain from manganese reductions, Science and Technology of Welding and Joining, UK, v. 11, n.1, p. 9-18, 2006.

[16] KEEHAN, E., L.KARLSOON, L.; ANDREN ,H.O., Influence of $\mathrm{C}, \mathrm{Mn}$ and $\mathrm{Ni}$ contents on microstructure and properties of strong steel weld metals, Part III - Increased strength from carbon additions, Science and Technology of Welding and Joining, UK, v. 11, n. 1, p. 19-24, 2006.

[17] JORGE, J.C.F, SOUZA,L.F.G, SANTOS FILHO,O.R., SANTOS FILHO,A.M; BOTT,I.S., Influência da composição química e tratamento térmico pós-soldagem nas propriedades mecânicas e microestruturais de metais de solda de alta resistência, IN: CONGRESSO NACIONAL DE SOLDAGEM, $33^{0}, 2011$, Caxias do Sul, Anais..., 2007, p. 1-10.

[18] FARAGASSO, S.M., SOUZA, L.F.G., BOTT, I.S.; JORGE,
J.C.F., Avaliação de Propriedades Mecânicas e Microestruturais de Metal de Solda de Aço de Extra Alta Resistência para Utilização em Equipamentos de Ancoragem, IN: CONGRESSO NACIONAL DE SOLDAGEM, 370, 2011, Natal, Anais..., 2011, p. 1-10.

[19] JORGE, J.C.F., SOUZA, L.F.G., SANTOS FILHO, O.R.; BOTT, I.S., Estudo de Metais de Solda de Aço de Extra Alta Resistência para Utilização em Componentes de Ancoragem de Plataformas de Petróleo, Parte I: Propriedades Mecânicas, IN: CONGRESSO NACIONAL DE SOLDAGEM, 37², 2011, Natal, Anais..., 2011, p. 1-10.

[20] GOMES, A.J.M., JORGE, J.C.F., SOUZA, L.F.G.; BOTT, I.S., Estudo comparativo de metais de solda de aços de extra alta resistência para utilização em componentes de linhas de ancoragem de plataformas de petróleo,

IN: CONGRESSO INTERNACIONAL DA ABM, 670 , 2012, Rio de Janeiro, Anais..., 2012, p. 806-818.

[21] ASTM INTERNATIONAL; Standard Test Methods and Definitions for Mechanical Testing of Steel Products, ASTM A-370-07a, USA, 2005.

[22] AMERICAN BUREAU OF SHIPPING, Rules for Materials and Welding, Part 2, USA, 2012.

[23] VERCESI, J.; SURIAN,E.S., The effect of welding parameters on high-strength SMAW all-weld-metal - Part 1: AWS E11018M, Welding Journal, USA, v. 75, n. 6, p.191-s196-s, Jun., 1996.

[24] VERCESI, J.; SURIAN,E.S., The effect of welding parameters on high-strength SMAW all-weld-metal. Part 2: AWS E10018M and E12018M, Welding Journal, USA, v. 77, n. 4, p.164-s-171-s, Apr., 1997.

[25] RAMIREZ, J.E., Characterization of high strength steel weld metals, chemical composition, microstructure and nonmetallic inclusions, Welding Journal, USA, v. 87, n. 3, p.65s75s, Mar., 2008.

[26] EVANS, G. M, The Effect of Nickel on the Microstructure and Proprieties of C-Mn All-Weld Metal Deposits, Welding Research Abroad, USA, v. 27, n. 2/3, p.70-83, Mar., 1991.

[27] EVANS,G.M., Development of MMA electrodes for offshore application, Metal Construction., v.15, n.7, p. 438443, Aug., 1983.

[28] SURIAN, E.S., TROTTI,J., CASSANELLI,A., de VEDIA,L.A., Influence of chromium element on mechanical properties and microstructure of weld metal from a high strength SMA electrode, Welding Journal, USA, v. 73, n. 3, p.45s-53s, Mar., 1994.

[29] JORGE, J.C.F. REBELLO, J.M.A.; SOUZA, L.F.G., The effect of chromium on the microstructure/toughness relationship of C-Mn weld metal deposits, Materials Characterization, USA, v.47, n.3/4, p.195 - 205, Sep.-Oct., 2001.

[30] EVANS, G.M., The Effect of Chromium on the Microstructure and Properties of C-Mn All-Weld Metal Deposits. Welding Research Abroad, USA, v. 27, n. 2/3, p.56-69, Mar., 1991.

[31] SURIAN, E.S., TROTTI, J., CASSANELLIi, A. N.; de VEDIA, L. Influence of Mn content on mechanical properties and microstructure of a high strength SMA electrode weld 
metal, IN: IIW Intermediate Meeting; 1987, Rio de Janeiro, Proceedings... 1987, IIW Doc. II-A-724-87.

[32] SURIAN, E.S., TROTTI, J., HERRERA, R.; de VEDIA, L. A., Influence of $\mathrm{C}$ on mechanical properties and microstructure of weld metal from a high-strength SMA electrode, Welding Journal, USA, v. 70, n. 6, p.133-s- 140-s, Jun.1991.

[33] SURIAN, E.S., RISSONE, M. R.; de VEDIA, L.A., Influence of molybdenum on ferritic high-strength SMAW AllWeld-Metal properties, Welding Journal, USA, vol. 84, No. 4, p.53s-62s, Apr., 2005.

[34] SALVADOR, L. S.; JORGE, J. C. F.; BOTT, I. S.; Efeito da Composição Química e Tratamento Térmico de Alívio de Tensões nas Propriedades de Metais de Solda de Alta resistência para Aplicação em Estruturas Offshore, IN: ENCONTRO NACIONAL DE TECNOLOGIA DA SOLDAGEM, 210 1995 , Caxias do Sul, Anais..., 1995, p.337 - 351.

[35] JORGE, J. C. F.; REBELLO, J. M. A.; Influence of welding procedure on the microstructure and toughness of high strength ferritic steel weld metals, Revue de la Soudure, Belgium, v. 56, n. 1, p.4-12, Mar., 2000.

[36] SALVADOR, L.S.F.; JORGE,J.C.F, Avaliação de consumíveis para soldagem de risers de completação,

IN: SIMPÓSIO LATINO AMERICANO SOBRE TUBULAÇÕES E VASOS DE PRESSÃO, $2^{0}$, 1994, Gramado, Anais..., 1994, p.315-324.

[37] MOsciaro, H. B. e JORGE, J. C. F., Propriedades Mecânicas de Reparos Por Soldagem de Aço Fundido de Alta Resistência, , IN: ENCONTRO NACIONAL DE TECNOLOGIA DA SOLDAGEM, 210, 1995 , Caxias do Sul, Anais..., 1995, p.307-317.

[38] TRINDADE, V. B.; PARANHOS, R. P. R.; PAYÃO, J. C.; SOUZA, L. F. G.; Influência da Adição de Níquel na Tenacidade de Metais de Solda de Aços C-Mn Antes e Após Tratamento Térmico de Alívio de Tensões, Soldagem \& Inspeção, Brasil, v. 10, n. 4, p. 164-171, dez., 2005.

[39] VIEIRA,L.A., Avaliação da tenacidade após tratamento térmico de alívio de tensões em soldas produzidas com arames tubulares rutílicos que contenham níquel., 2006, 65p., Dissertação de Mestrado, Escola de Engenharia, Universidade Federal de Minas Gerais, Minas Gerais, Brasil.

[40] VOGAS, P.V.B.D., JORGE, J.C.F., SOUZA, L.F.G. e BOTT, I.S., Efeito do tratamento térmico pós-soldagem nas propriedades de metal de solda de alta resistência obtidos por arame tubular tipo flux cored, IN: CONGRESSO INTERNACIONAL DA ABM, $67^{\circ}, 2012$, Rio de Janeiro, Anais..., 2012, p.374-387. 